\title{
SCAN TO BIM FOR 3D RECONSTRUCTION OF THE PAPAL BASILICA OF SAINT FRANCIS IN ASSISI IN ITALY
}

\author{
M. G. Angelini ${ }^{\text {a, }}$ V. Baiocchi ${ }^{b}$, D. Costantino ${ }^{\text {a, } *, \text { F. Garzia }^{c}}$ \\ ${ }^{a}$ DICATECh, Politecnico di Bari, Italy, 70126 Bari, Italy - (domenica.costantino, mariagiuseppa.angelini)@ poliba.it \\ ${ }^{\mathrm{b}}$ DICEA, SAPIENZA - University of Rome, 00184 Roma, Italy - valerio.baiocchi@ uniroma1.it \\ ${ }^{c}$ Safety \& Security Engineering Group - DICMA, SAPIENZA - University of Rome, 00184 Roma, Italy \\ fabio.garzia@uniroma1.it
}

Commission VI, WG VI/4

KEY WORDS: Laser scanning, BIM, Assisi, Point clouds, Security and safety management, Internet of Things, Internet of Everything

\begin{abstract}
:
The historical building heritage, present in the most of Italian cities centres, is, as part of the construction sector, a working potential, but unfortunately it requires planning of more complex and problematic interventions. However, policies to support on the existing interventions, together with a growing sensitivity for the recovery of assets, determine the need to implement specific studies and to analyse the specific problems of each site. The purpose of this paper is to illustrate the methodology and the results obtained from integrated laser scanning activity in order to have precious architectural information useful not only from the cultural heritage point of view but also to construct more operative and powerful tools, such as BIM (Building Information Modelling) aimed to the management of this cultural heritage. The Papal Basilica and the Sacred Convent of Saint Francis in Assisi in Italy are, in fact, characterized by unique and complex peculiarities, which require a detailed knowledge of the sites themselves to ensure visitor's security and safety. For such a project, we have to take in account all the people and personnel normally present in the site, visitors with disabilities and finally the needs for cultural heritage preservation and protection. This aim can be reached using integrated systems and new technologies, such as Internet of Everything (IoE), capable of connecting people, things (smart sensors, devices and actuators; mobile terminals; wearable devices; etc.), data/information/knowledge and processes to reach the desired goals. The IoE system must implement and support an Integrated Multidisciplinary Model for Security and Safety Management (IMMSSM) for the specific context, using a multidisciplinary approach.
\end{abstract}

\section{INTRODUCTION}

Historic monumental buildings subject to be recovered and/ or restored can be characterized by considerable artistic, architectural and cultural features and they can, at the same time, be subject to constraints on the possible interventions and/ or on the modalities of execution of the same interventions.

Thus, when it is needed to operate on existing artifacts it is necessary to intervene with specific techniques and precautions, integrating the different related activities. The project, therefore, will result in the coordinated synthesis of a complex of integrated multidisciplinary activities. Synthesis starts from a careful and detailed relief phase followed by a deep study of the historic evolution of the building itself. Subsequently, the next step is represented by the planning of interventions and finally by the management of the planned operations.

To achieve an integrated project, i.e., integrate and manage each project phase and management (surveying, architectural design, restoration project, the design of the different installations, the construction project, resource management, management of the result) a BIM (building Information Model) approach becomes indispensable. A BIM model is characterized by the composition of digital objects that can be associated to parameters and rules of operation and connection between the different elements and between the elements and the building.
In the preliminary relief phase, the use of the laser scanner and the management of the model in a BIM based methodology simplifies the organization of the interventions on constructed by integrating the metric information with the possibility to simulate the subsequent stages. The BIM model, based on digital survey data, becomes a real representation, not only of the single object, but also of the entire construction intervention. From the model, it will be possible extract, manage and control the individual aspects of interest of the different professionals involved, such as security, qualities or material issues. All these informations are, in this way, shared and collected in a single database continuously updated.

\section{THE PAPAL BASILICA AND THE SACRED CONVENT OF SAINT FRANCIS IN ASSISI}

The Papal Basilica and the Sacred Convent of St. Francis in Assisi (Italy) represent a unique and peculiar cultural heritage site where the mortal remains of St. Francis are housed since $1230 \mathrm{AD}$.

Millions of pilgrims and visitors coming from all over the world visit this site each year that, from $2000 \mathrm{AD}$, together whit other Franciscan sites in the surrounding, have been appointed as World Heritage by UNESCO.

\footnotetext{
* Corresponding author
} 
The Papal Basilica (figg. 1, 2), where unique frescos by Giotto and other famous painters are present, is composed by three

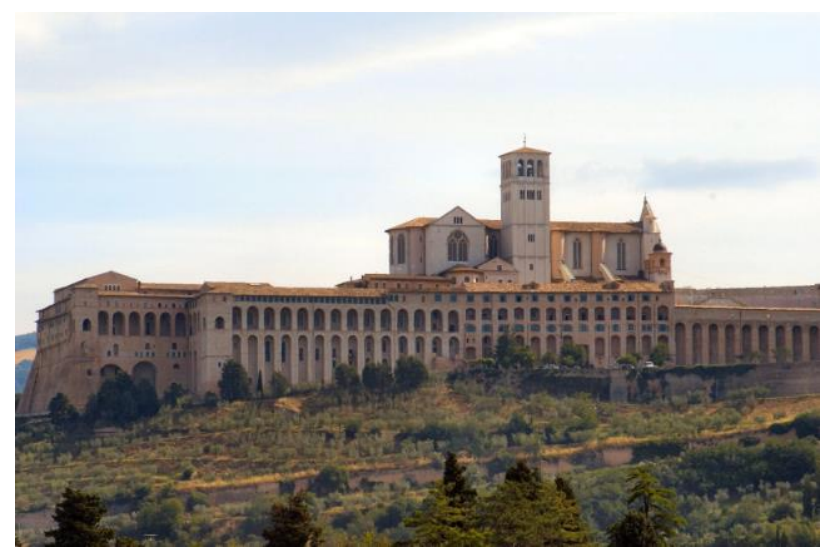

Figure 1. Panoramic view of the Papal Basilica and the Sacred of Assisi

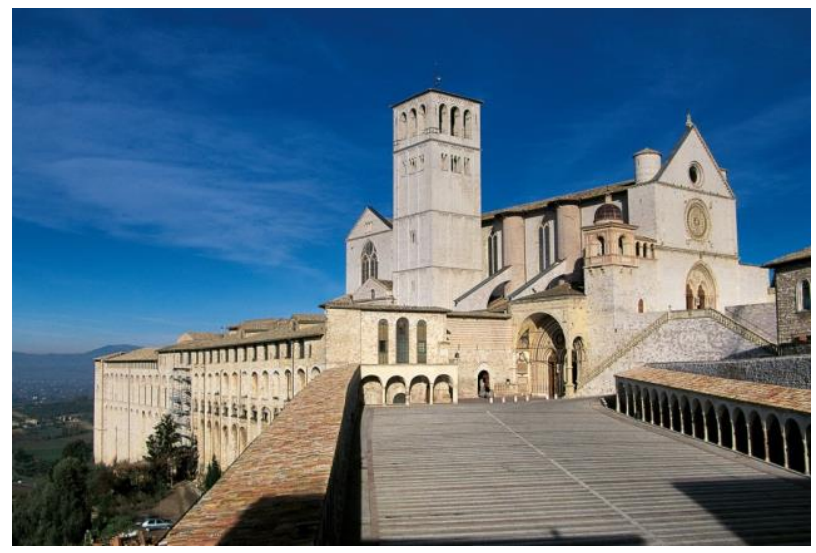

Figure 2. View of the lower square and the Basilica

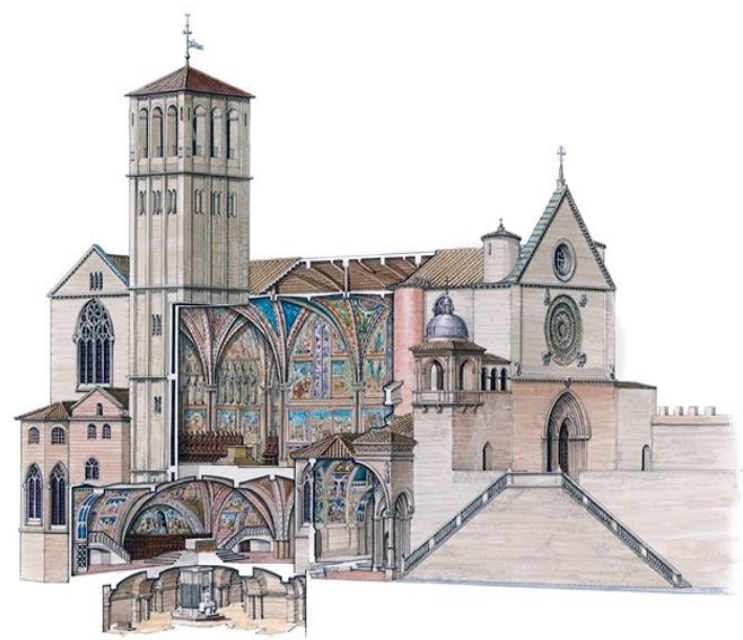

Figure 3. View of the 3 layers of the Basilica (left) and the related plants (up-right: higher Basilica, down-right: lower Basilica)

main stratified structures (fig. 3):

1) the tomb of St. Francis (fig. 4), located at the lower level;
2) the lower Basilica (fig. 5), whose altar is just above the tomb of St. Francis;

3) the upper Basilica, located above the lower Basilica. Inside the Sacred Convent are also present a museum, a library and a plenty of places where spiritual and cultural activities are hosted.

On September 26, 1997, a powerful earthquake struck the Basilica causing the collapse of some of the frescoes and the vaults of the Upper Basilica of St. Francis in Assisi. In particular, the vault of the first span was damaged with the St. Jerome fresco (attributed by some to a young Giotto), where the Four Doctors of the Church were shown. The figure of St. Matthew, on the ceiling depicting the Four Evangelists by Cimabue was damaged too. Moreover, the starry vault, repainted in the nineteenth century was destroyed. On the arch of the counter and on the rib, part of the eight figures of saints and other decorations collapsed too.

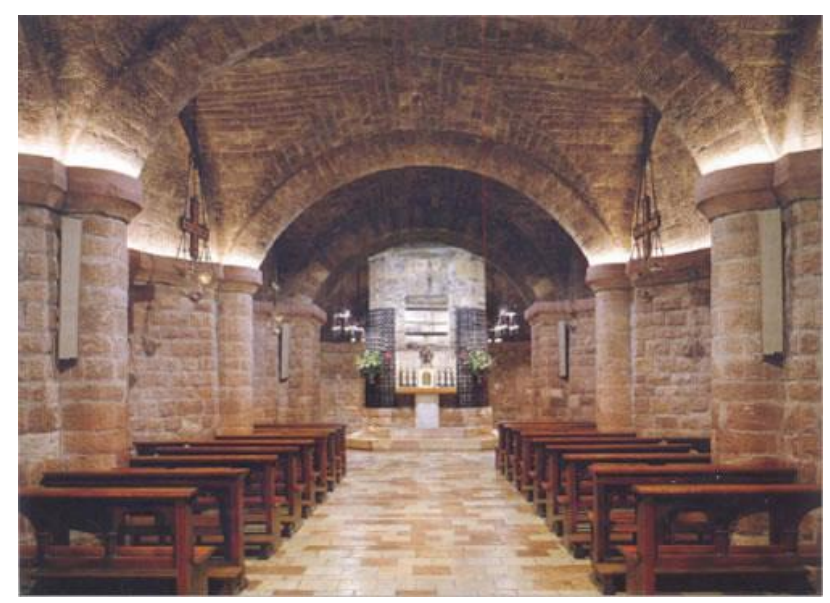

Figure 4. View of the tomb of Saint Francis

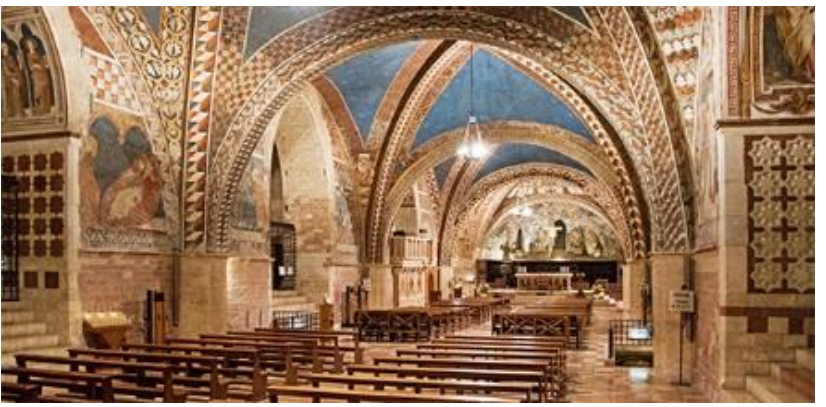

Figure 5. View of the interior of the lower Basilica

The first post-earthquake interventions were aimed mainly to the safety of the sacred building and to the recovery of hundreds of fragments scattered in the rubble. The Basilica was closed until November $29^{\text {th }} 1999$ for the conservation and restoration works (fig. 6).

\section{THE LASER SCANNING ACTIVITY}

Even if all the "classical" Geomatiques techniques can perfectly fulfill many crucial monument survey needs, there are still many cases where they show some limits. Most of the difficulties are related to the morphologic and architectural accessibility (Baiocchi, 2014; Dardanelli, 2017).

In order to realize a three-dimensional model of the Basilica an integrated techniques survey activity was performed as it's often needed in such studies (Ercoli 2016; Brigante, 2014; Di salvo, 2014; Dominici, 2013); the planning has been based on the available bi-dimensional maps (fig. 7). 


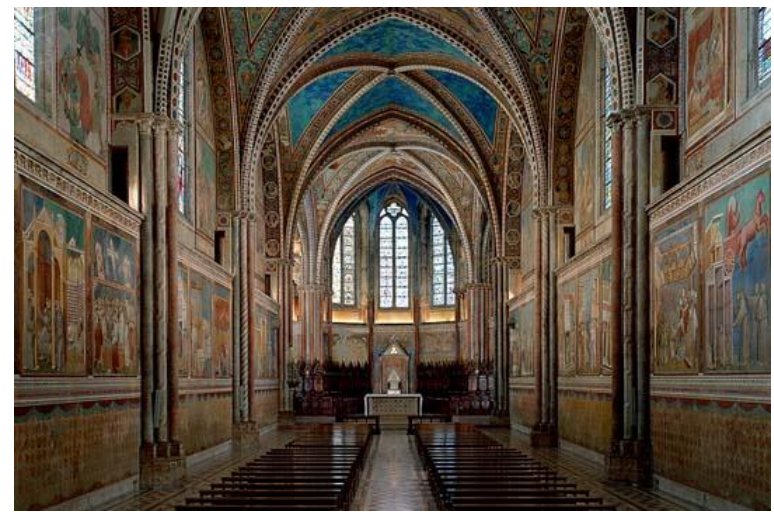

Figure 6. View of the interior of the upper Basilica after restoration

In particular, measurements were performed using: GNSS (Global Navigation Satellite Systems) receivers, topographic total stations, terrestrial laser scanning (TLS) and photogrammetry.
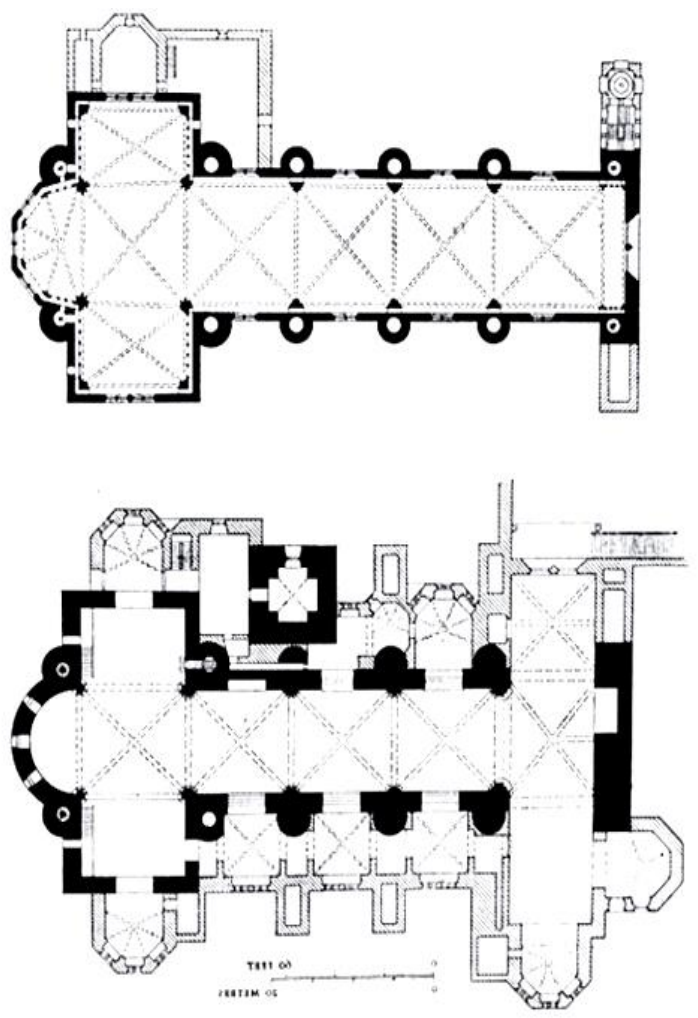

Figure 7. Bi-dimensional maps

The control network used as reference system to the UTM WGS84 ETRF2000 Datum as required by national legislation (Barbarella, 2014). For this purpose, some points external to the Basilica have been surveyed using rapid static GNSS methodology. Starting from GNSS points different traverses were realized to branch out on the three upper levels of the Basilica. The definition of the vertices of the traverses station have been chosen considering the visibility of the laser targets and natural points to be measured. The latter activity is necessary for the subsequent alignment of laser scans and the subsequent geo-referencing of their data.

The TLS survey was performed only for the three main parts of the monumental complex: crypt, the lower basilica and the upper basilica, presently service and connection spaces were not surveyed.
To ensure the coverage of the above spaces and to minimize the shadow areas, 33 laser acquisitions (fig. 8) have been realized: 8 in the crypt, 18 for the lower church (including the side chapels) and 7 for the upper basilica.

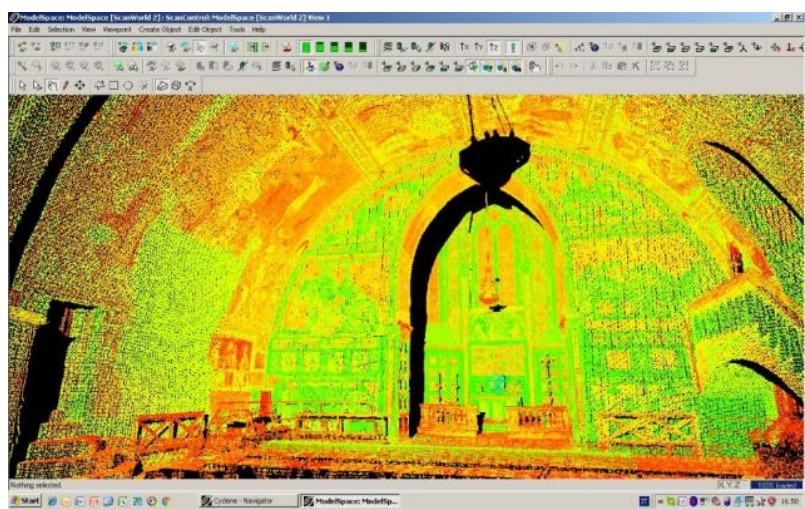

Figure 8. Single scan
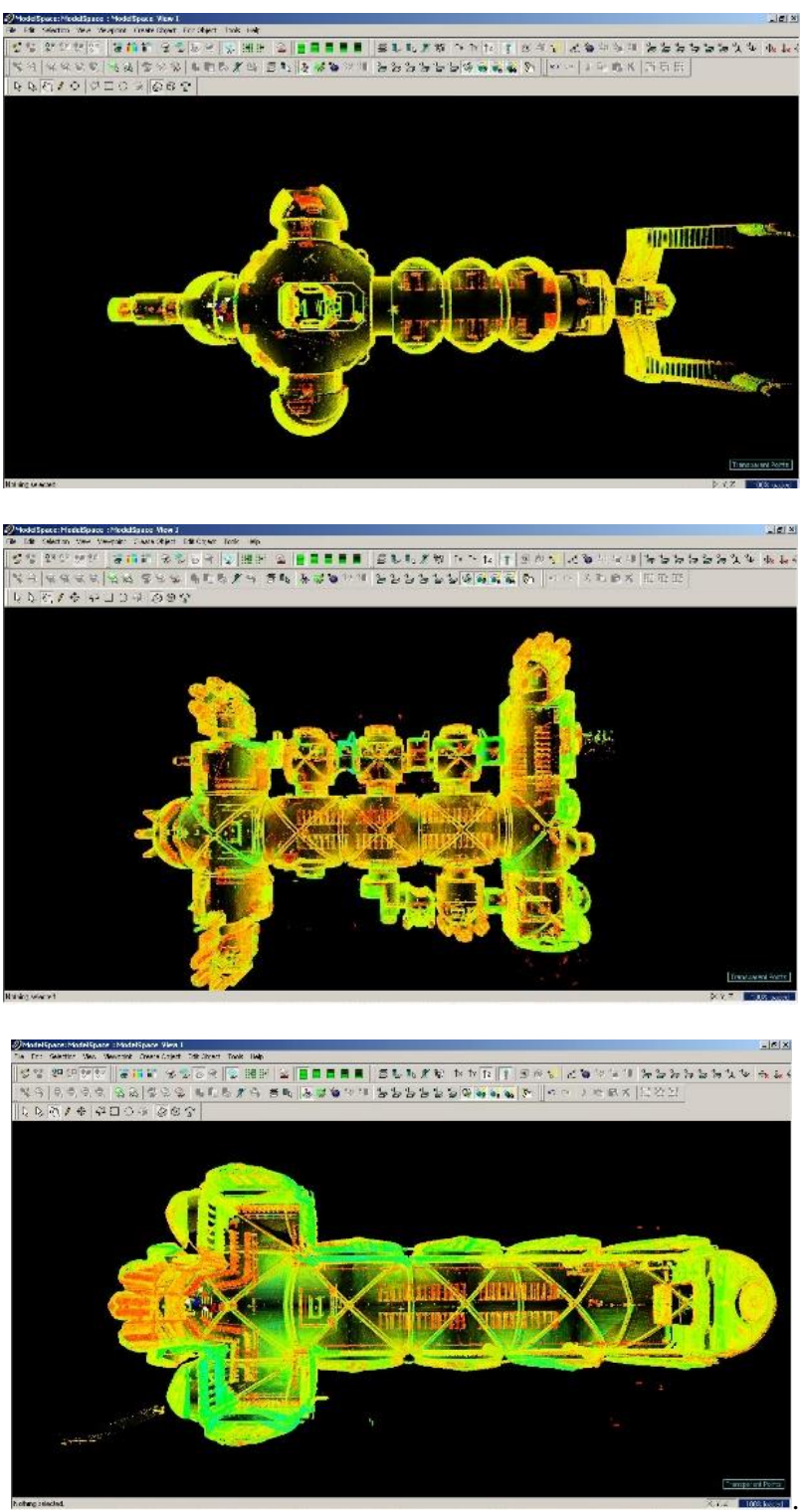

Figure 9. Point clouds of Crypt (upper figure), lower Basilica (medium figure) and upper Basilica (lower figure) 
The acquisition and the registration of the scans, performed for the individual spaces, has been realized by means of the Cyclone software, proceeding, at first to the alignment between the different scans referring to each space and, subsequently, to their georeferencing (fig. 9).

In order to convert the point cloud into a final 3D model, it has been exported to ".xyz" format and then imported into "Geomagic" software format. A pre-processing of the cloud was performed by applying some of the filters available in the software, in particular, those most closely related to the type of survey and it was later carried out the meshing process. To optimize the results, the surface model was again filtered and, where possible, the "closure of the holes" was performed (fig. $10)$.

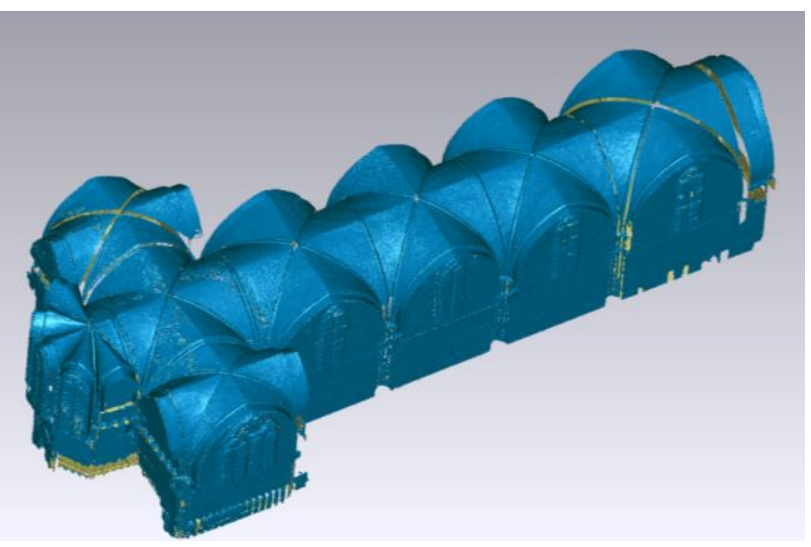

Figure 10. Meshing upper basilica

The obtained models were converted into several formats to allow exporting them in open source (fig. 11) or CAD software. To get 2D representations (planimetric, transverse and longitudinal), and to obtain metrically correct maps, an experimental numerical algorithm, developed in $\mathrm{C}++$ was used (Costantino, 2010a). In particular, from the point cloud, infinitesimal portions consistent with section planes have been selected, generating a set of 2D two-dimensional points converted later by a subsequent vectorialization algorithm and exported finally to ".dxf" format (fig. 12) (Costantino, 2011; Costantino, 2010b; Costantino, 2015; Costantino, 2012).

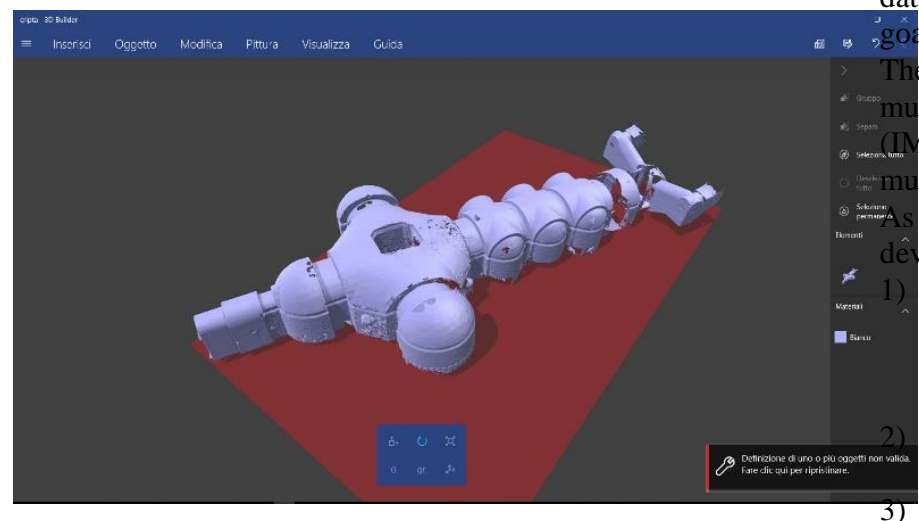

Figure 11. Representation of one of the models in an open source environment

The photogrammetric survey, for three-dimensional reconstruction of the frescoes was started, employing the Structure from Motion (SfM) photogrammetric algorithms that are efficiently used for these specific applications in recent studies (Caroti, 2015; Costantino, 2016; Baiocchi, 2017; Troisi, 2017) as reported in figure 13.

\section{gon $x$}

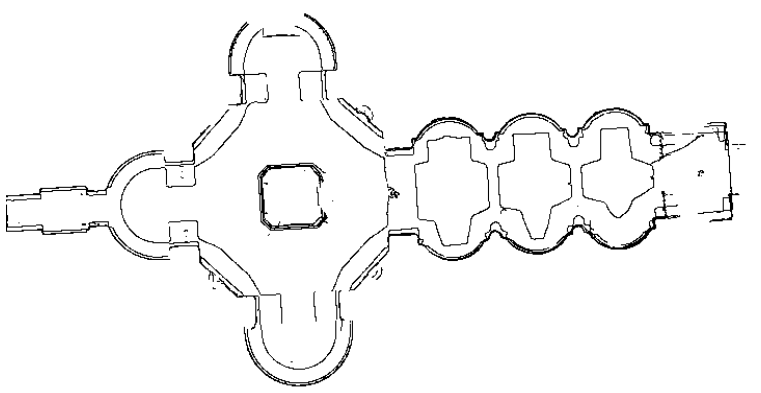

Figure 12. 2D Representation

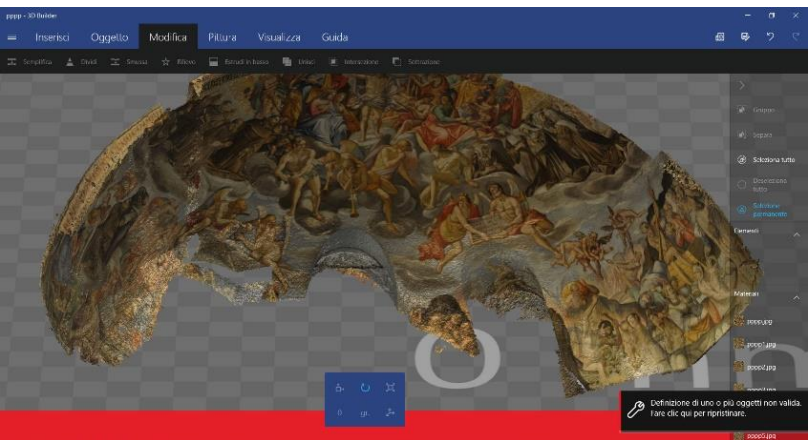

Figure 13. The frescoes vault photogrammetric reconstruction

\section{INTERNET OF EVERYTHING SYSTEM}

Peculiar, unique and complex cultural heritage sites, such as the considered one, need a great effort to ensure visitors security and safety, cultural heritage preservation and protection and great usability for visitors (D' Urso, 2014) with particular reference to visitors with disabilities and for all the people and personnel normally present for the site management.

This aim can be reached using integrated systems (Garzia, 2011; Contardi, 2011; Garzia, 2012a; Garzia, 2012b; Garzia, 2012c) and new technologies, such as Internet of Everything (IoE), capable of connecting people, things (smart sensors, devices and actuators; mobile terminals; wearable devices; etc.), ata/information/knowledge and processes to reach the desired ls (Garzia, 2016a; Garzia, 2016b).

IoE system must implement and support an integrated tidisciplinary model for security and safety management MSSM) (Garzia, 2016c) for the specific context, using a tidisciplinary approach whose scheme is shown in figure 14 . it is possible to see from figure 14, the IMMSSM is eloped according to the following points:

Risks analysis (qualitative, semi-quantitative, quantitative and mixed including human factors) to evaluate all the threats (Lombardi, 2013; Guarascio, 2007; Guarascio, 2013; Broder 2012).

Impact analysis to evaluate the damages generated by the above threats.

Risks mitigation.

4) Residual risks management.

5) Risks mitigation can be done using fundamental operative tools (OTs) represented by:

6) Countermeasures: physical/logical technology, and physical/logical barriers (Garzia, 2013).

7) Security policies and procedures, considering also human factor (Borghini, 2016). 


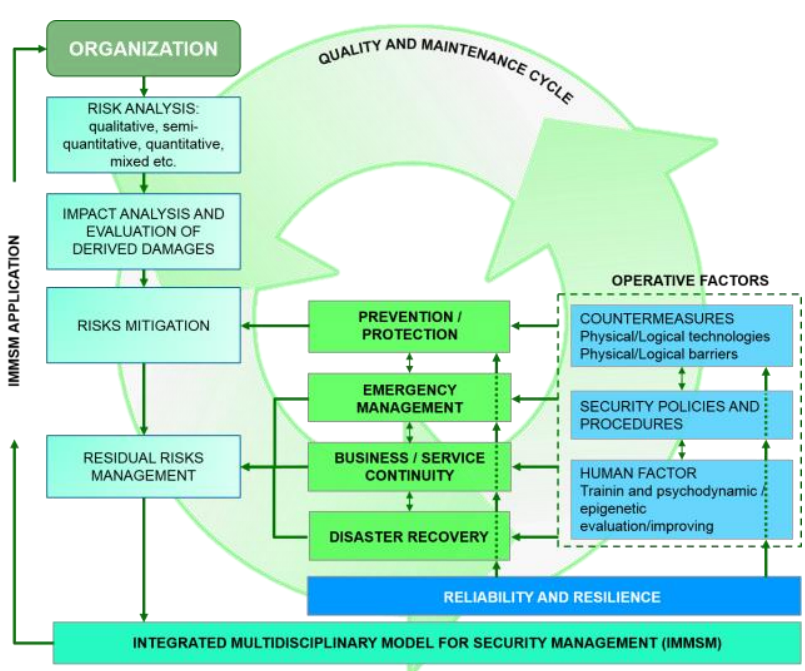

Figure 14. Scheme of the integrated multidisciplinary model for security and safety management

Residual risk management can be done using fundamental tools, aided by OTs, represented by:

a) Emergency management.

b) Service and business continuity.

c) Disaster recovery.

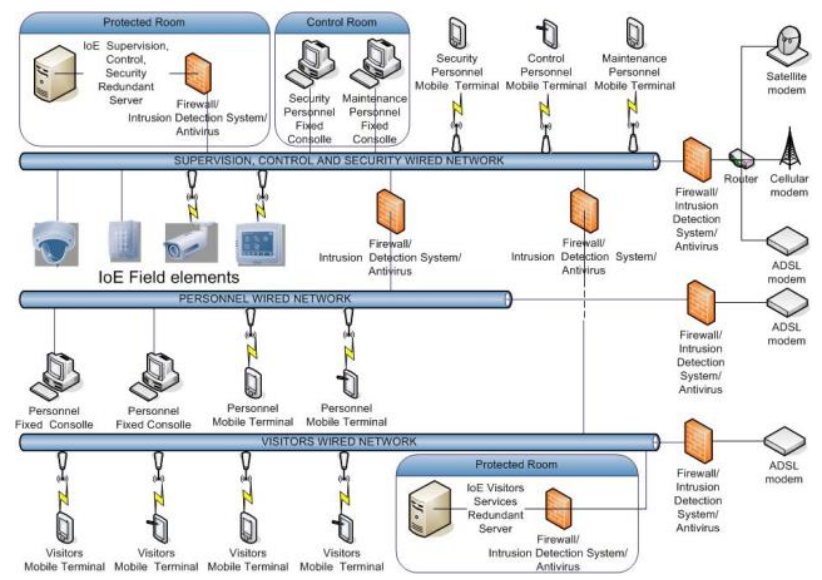

Figure 15. Scheme of the IoE based integrated technological system framework (IoE-ITSF) to support the integrated multidisciplinary model for security and safety management (IMMSSM)

To support the IMMSSM, it is necessary to have a proper Integrated Technological System Framework (ITSF) that can ensure the full functionalities of the IMMSSM with high flexibility and modularity, so that it is possible at any time to translate any eventual modification of the IMMSSM into a fast and low-cost modification of the ITSF.

The general architecture of the IoE based integrated technological system framework (IoE-ITSF) is shown in figure 15 .

\section{BUILDING INFORMATION MODELING}

The point cloud obtained from processing in Geomagic was exported in ASCII format and, subsequently, imported into Autodesk RECAP 360 (fig. 16), which retains the georeferencing informations. After this step, the unification of the scans and the export in a format compatible with Revit environment were performed. According to Baik (2013) the resons to use Autodesk Revit are "fast built and modify to 3D model, high quality construction documents and advance level of flexibility".
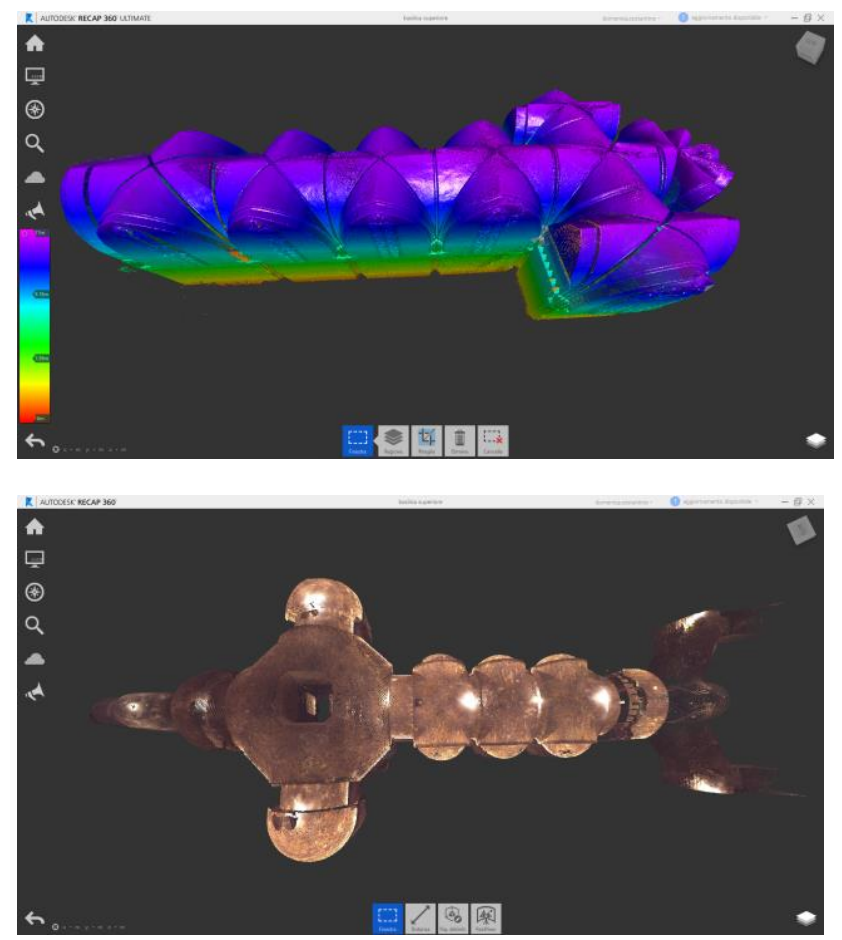

Figure 16. Point cloud of the upper basilica (up) and of Crypt (down) in RECAP 360

The point cloud has then been linked in Revit (Figs. 17, 18) to proceed with the "scan to BIM" approach, which involves the insertion of data resulting from a TLS survey in a BIM model. This is an effective methodology that allows you to get a true view of the locations, a prerequisite for choosing the methodology of intervention. It also allows a perfectly integrated control of the works, costs and execution times.
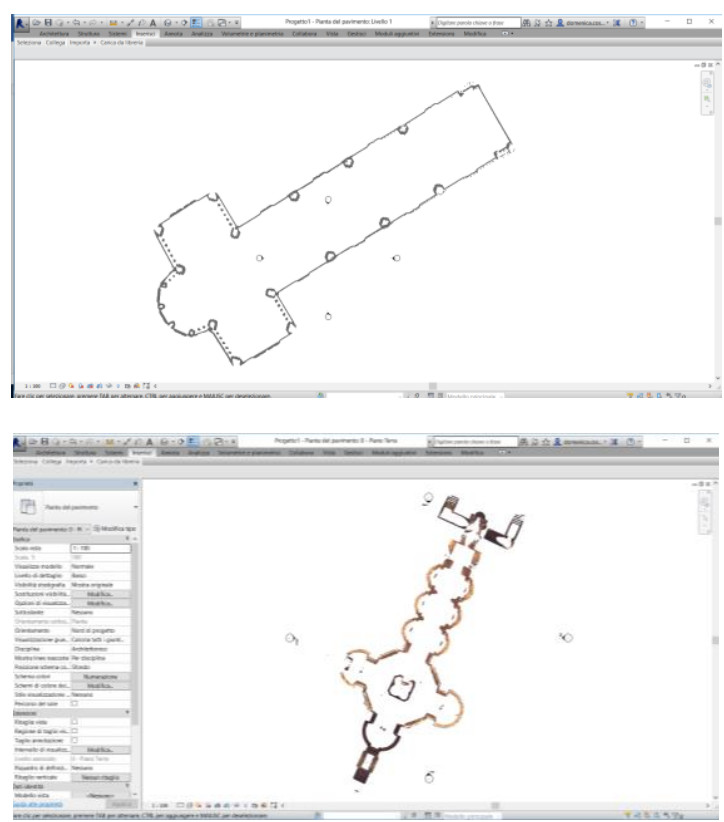

Figure 17. Upper Basilica (up) and Crypt (down) point clouds represented in Revit $2 \mathrm{D}$ mode 


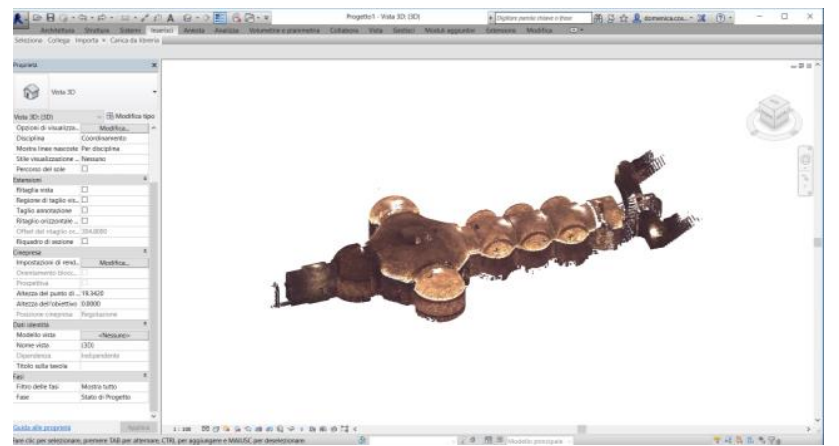

Figure 18. Crypt cloud point represented in Revit environment

The cloud points total was subsequently used as a guideline in order to draw the main structural components (walls, floors, vault, steps, etc.), as shown in figure 19.
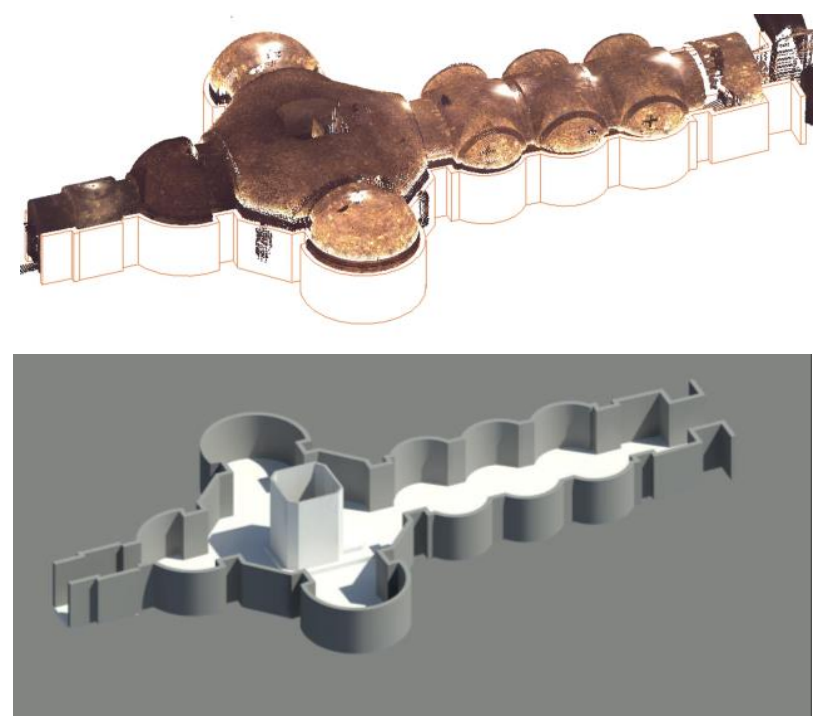

Figure 19. Inserting (up) and 3D rendering (down) of the wall of the Crypt in Revit environment

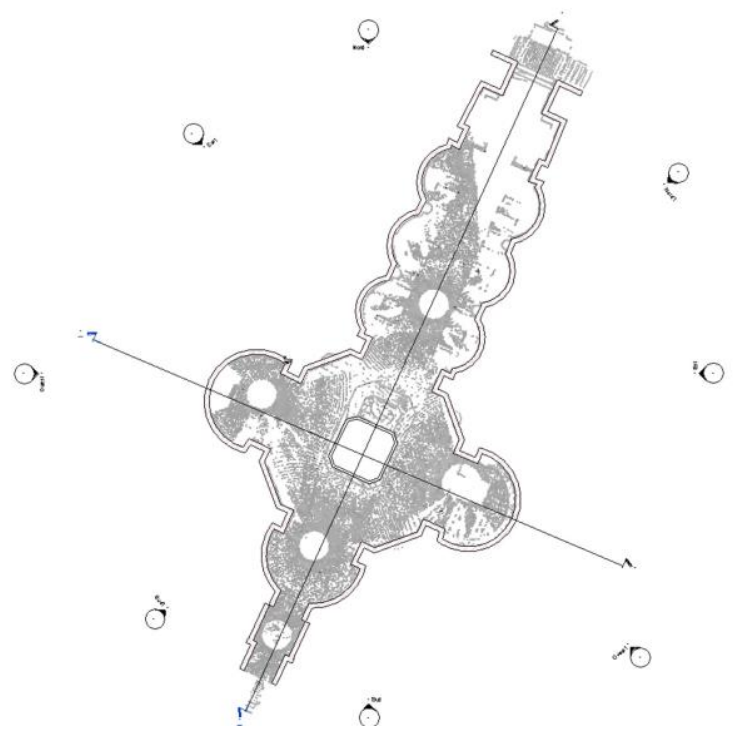

Figure 20. Lines of transverse and longitudinal sections of the Crypt in Revit environment

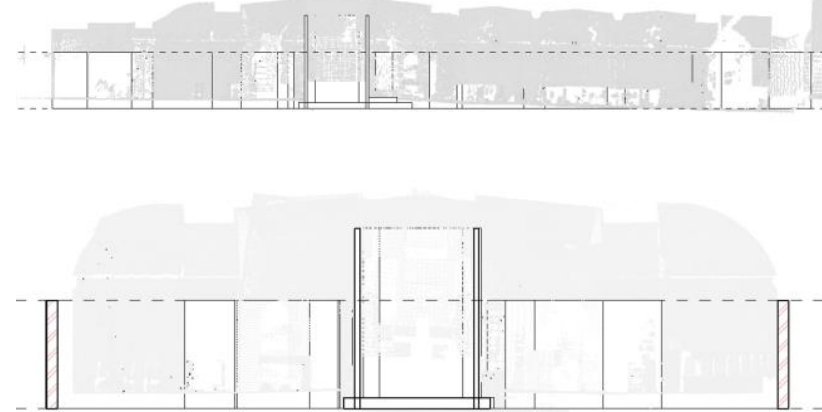

Figure 21. Longitudinal (up) and transverse (down) type section of the Crypt in Revit environment

For the modelling of the vault elements, considering that the approach of Building Information Modelling are applied usually to designing new buildings and new innovations, many problems arise in relation to modelling historic buildings and also generating BIM models from laser scan survey data. In fact, is not possible, to associate the generic library objects of BIM environment with laser scanning data, therefore, the approach is to create a parametric libraries in order to improved plotting of objects onto the scan surveys. In this work, the first result of this approach are shown(fig. 22).

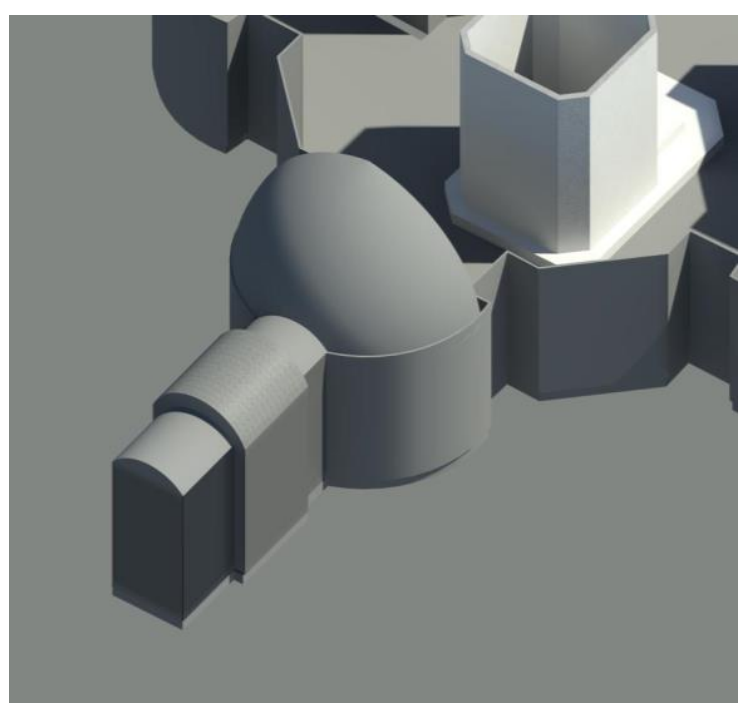

Figure 22. Parametric libraries for vault in first step

\section{CONCLUSIONS}

The first modelling of a so big amount of data represents the preliminary results. The survey operations allowed to evidence critical points and correct procedures. Obviously, a big part of the work has still to be made to correctly manage and model the data to obtain a complete geographic database as the scientific technological community (Costantino, 2010b) presently requests it.

Due to the presence of strong architectural vincula, it is necessary to take particular care in wires and devices installation (Garzia, 2013) and for this reason all the information deriving from laser scanning becomes fundamental. The methodology and the results obtained from the just started laser scanning activity in the Papal Basilica and Sacred Convent of Saint Francis in Assisi have been illustrated. 
They represent a fundamental activity that allows obtaining precious architectural information useful not only from the cultural heritage point of view but also for more operative and powerful tools, such as BIM (Building Information Modelling), where all the information will be transferred later.

These subsequent activities are vital to create a proper Integrated Multidisciplinary Model for Security and Safety Management (IMMSSM) that allows the consequent design and realization of the related $\mathrm{IoE}$ based integrated technological system that implements and supports it.

\section{REFERENCES}

Baik, A., Boehm, J., Robson, S., 2013. Jeddah Historical Building Information Modelling "JHBIM" Old Jeddah - Saudi Arabia

Baiocchi, V., Barbarella, M., Del Pizzo, S., Giannone, F., Troisi, S., Piccaro, C., and Marcantonio, D., 2017. Augusto's sundial: image-based modeling for reverse engeneering purposes, Int. arch. photogramm. remote sens. spatial inf. sci., XLII-2/W3, 63-69, doi:10.5194/isprs-archives-XLII-2-W3-63$2017,2017$.

Baiocchi, V., Dominici, D., Milone, M.V., Mormile, M., 2014. Development of a software to optimize and plan the acquisitions from UAV and a first application in a post-seismic environment. European Journal of Remote Sensing, 47 (1), pp. 477-496.

Barbarella, M., 2014. Digital technology and geodetic infrastructures in Italian cartography. Citta e Storia, 9(1), pp. 91-110.

Borghini, F., Garzia, F., Borghini, A. \& Borghini, G., 2016. The Psychology of Security. Emergency and Risk, WIT Press.

Brigante, R., Radicioni, F.: Metric-historical studies for the monitoring of the walls of Amelia, Citta e Storia, Volume 9, Issue 1, 1 March 2014, Pages 111-129

Broder, J. F. \& Tucker, E., 2012. Risk Analysis and the Security Survey. Buttherwoth-Heinemann, New York.

Caroti, G., Martínez-Espejo Zaragoza, I., and Piemonte, A. 2015. Range and image based modelling: a way for frescoed vault texturing optimization, Int. Arch. Photogramm. Remote Sens. Spatial Inf. Sci., XL-5/W4, 285-290, doi:10.5194/isprsarchives-XL-5-W4-285-2015, 2015.

Contardi, G., Garzia, F. \& Cusani, R., 2011. The integrated security system of the Senate of the Italian Republic. International Journal of Safety \& Security Engineering, 1(3), pp. 219- 246, 2011.

Costantino D, Angelini M. G., Milan N., 2011. 3D documentation and visualization of cultural heritage. XXIII International CIPA Symposium, Prague, CD ROM, ISBN: 97880-01-04885-6.

Costantino, D., Angelini, M.G., 2010a. Realization of a cartographic GIS for the filing and management of the archaeological excavations in the Nelson's Island. Lecture Notes in Computer Science, 6436, pp. 513-527.
Costantino, D., Angelini, M.G., 2012. Process modeling and photogrammetric production for structural investigations concerning to the collapse of Palazzo Edilizia in Salerno (Italy). Lecture Notes in Computer Science, 7616 LNCS, pp. 440-448.

Costantino, D., Angelini, M.G., 2015. Three-Dimensional Integrated Survey for Building Investigations. Journal of Forensic Sciences, 60 (6), pp. 1625-1632.

Costantino, D., Angelini, M.G., Caprino, G., 2010b. Laser scanner survey of an archaeological site - Scala di Furno (Lecce, Italy). International Archives of the Photogrammetry, Remote Sensing and Spatial Information Sciences, 38 (PART 5), pp. 178-183.

Costantino, D., Angelini, M.G., Mazzone, F., 2016. Integrated survey methodology for the crime reconstruction. Imaging Science Journal, 64 (6), pp. 341-351.

Dardanelli G., Allegra M., Giammarresi V., Lo Brutto M., Pipitone C., Baiocchi V., 2017. Geomatic methodologies for the study of Teatro Massimo in Palermo (Italy), International Archives of the Photogrammetry, Remote Sensing and Spatial Information Sciences,,,,

Di Salvo, F., Lo Brutto, M.: Full-waveform terrestrial laser scanning for extracting a high-resolution 3D topographic model: A case study on an area of archaeological significance, European Journal of Remote Sensing, Volume 47, Issue 1, 10 May 2014, Pages 307-327, DOI: 10.5721/EuJRS20144719

Dominici D., Rosciano E., Alicandro M., Elaiopoulos M., Trigliozzi S. and Massimi V., 2013. Cultural heritage documentation using geomatic techniques: Case study: San Basilio's monastery, L'Aquila, Digital Heritage International Congress (DigitalHeritage), Marseille, 2013, pp. 211-214. doi: 10.1109/DigitalHeritage.2013.6743735

D'Urso, M. G., Marino, C. L., and Rotondi, A.: On 3D Dimension: Study cases for Archaeological sites, Int. Arch. Photogramm. Remote Sens. Spatial Inf. Sci., XL-6, 13-18, doi:10.5194/isprsarchives-XL-6-13-2014, 2014.

Ercoli, M., Brigante, R., Radicioni, F., Pauselli, C., Mazzocca, M., Centi, G., Stoppini, A., 2016. Inside the polygonal walls of Amelia (Central Italy): A multidisciplinary data integration, encompassing geodetic monitoring and geophysical prospections, Journal of Applied Geophysics, 127, pp. 31-44. doi: 10.1016/j.jappgeo.2016.02.003

Garzia, F. \& Cusani, R., 2013. New technique for the optimization of security communication wired networks in historical buildings. Proceedings of the Fortieth Annual IEEE International Carnahan Conference on Security Technology, pp. 116-121.

Garzia, F. \& Cusani, R., The integrated safety / security / communication system of the Gran Sasso mountain in Italy. International Journal of Safety \& Security Engineering, 2(1), pp. 13-39, 2012a.

Garzia, F. 2016c. An Integrated Multidisciplinary Model for Security Management - Optimized Implementation Technique and Related Supporting Technological System Framework. Proceedings of the Fifty Annual IEEE International Carnahan Conference on Security Technology, pp. 107-114. 
Garzia, F., 2013. Handbook of Communication Security, WIT Press.

Garzia, F., Cusani, R., 2012b. The safety/security/communication wireless LAN of the underground Gran Sasso mountain national laboratories of the Italian Institute of Nuclear Physics. International Journal of Safety \& Security Engineering, 2(3), pp. 209-226,

Garzia, F., Papi, L., 2016a. An Internet of Everything based integrated security system for smart archaeological areas. Proceedings of the Fifty Annual IEEE International Carnahan Conference on Security Technology, pp. 64-71.

Garzia, F., Sammarco, E. \& Cusani, R., 2012c. Vehicle/people access control system for security management in ports. International Journal of Safety \& Security Engineering, 2(4), pp. 351-367.

Garzia, F., Sammarco, E. \&, Cusani, R., 2011. The integrated security system of the Vatican City State. International Journal of Safety \& Security Engineering, 1(1), pp. 1-17.

Garzia, F., Sant'Andrea, L., 2016b. The Internet of Everything Based Integrated Security System of World War I Commemorative Museum of Fogliano Redipuglia in Italy. Proceedings of the Fifty Annual IEEE International Carnahan Conference on Security Technology, pp. 56-63.

Guarascio, M., Lombardi, M. \& Massi, F., 2013. Risk Analysis in handling and storage of petroleum products. American Journal of Applied Sciences, 10(9), pp. 965-978.

Guarascio, M., Lombardi, M., Rossi, G. \& Sciarra, G., 2007. Risk analysis and acceptability criteria, WIT Transactions on the Built Environment, 94, pp.131-138.

Lombardi, M., Guarascio, M. \& Rossi, G., 2013. The management of uncertainty: Model for evaluation of human error probability in railway system. American Journal of Applied Sciences, 11(3), pp. 381-390.

Troisi, S., Baiocchi, V., Del Pizzo, S., and Giannone, F.: A prompt methodology to georeference complex hypogea environments, Int. Arch. Photogramm. Remote Sens. Spatial Inf. Sci., XLII-2/W3, 639-644, doi:10.5194/isprs-archivesXLII-2-W3-639-2017, 2017. 